\title{
Educação e diferença: diálogos e perspectivas
}

\author{
Jaqueline Barbosa da Silva' \\ Universidade Federal de Pernambuco, Campus Agreste, Professora Adjunta do Núcleo de \\ Formação Docente \\ https://orcid.org/0000-0002-0305-9716 \\ Everaldo Fernandes da Silua ${ }^{2}$ \\ Universidade Federal de Pernambuco, Campus Agreste, Professor Adjunto do Núcleo de \\ Formação Docente \\ https://orcid.org/0000-0002-8974-0878

\section{Eduardo Jorge Lopes da Silua ${ }^{3}$} \\ Universidade Federal da Paraíba, Centro de Educação, Professor Adjunto; Professor \\ Permanente do Programa de Pós-Graduação em Educação \\ https://orcid.org/0000-0002-5402-8880
}

As configurações históricas constituídas no processo de construção da identidade nacional brasileira expressam a herança colonizadora, representada por um sistema etnocêntrico, que invisibiliza as diferenças étnicas, raciais e culturais.

Com o processo de redemocratização do Brasil emerge a necessidade de reformulação dos marcos regulatórios da legislação educacional brasileira, impulsionada pela centralidade do debate étnico-racial e indígena.

Os movimentos sociais, indígenas e negros, passam a apontar a necessidade de se repensar a educação para além do modelo eurocêntrico. 0 debate das relações étnicoraciais passa a exigir a reformulação na legislação educacional brasileira, fazendo surgir, na década de 1990, uma série de documentos e novos marcos regulatórios.

A alteração da Lei de Diretrizes e Bases da Educação Nacional, n. 9.394 (BRASIL, 1996), incluindo a obrigatoriedade da temática História e Cultura Afro-Brasileira, com a promulgação da Lei n. 10.639 (BRASIL, 2003), e posteriormente a Lei n. 11.645 (BRASIL, 2008), acrescendo a terminologia Indígena, representa um primeiro movimento de reconhecimento para o desenvolvimento de políticas educacionais de promoção da igualdade étnico-racial.

Nesse cenário de conquistas legais, as geopolíticas educacionais e afirmativas aliam-se ao caráter político e popular das iniciativas vinculadas aos movimentos sociais negros e indígenas, passando a demandar uma agenda de lutas organizadas pela garantia e cumprimento de currículos específicos e diferenciados.

Doutora em Educação pela Universidade Federal de Pernambuco; Mestra em Educação pela mesma Universidade.

2 Doutor em Educação pela Universidade Federal de Pernambuco; Mestre em Teologia pela Faculdade Jesuíta de Filosofia e Teologia.

3 Doutor em Educação pela Universidade Federal de Pernambuco; Mestre em Educação pela Universidade Federal da Paraiba. 
A realização de estudos e procedimentos de pesquisa que se debruçam sobre coletivos sociais que conquistaram o direito à educação passa a ser considerada na produção acadêmico-científica, revelando-se em campo fértil para a realização de estudos, pesquisas e novas práticas educativas (GOMES, 2017; SANTIAG0 et al., 2010; GRUPIONI, 2000; SILVA, 2002).

Em meio a essas conquistas, pesquisadores da área, entre outros Almeida (2010) e Oliveira (2008), baseando-se nos documentos oficiais, preconizam a necessidade de institucionalização e implantação de políticas públicas para as relações étnico-raciais e indígenas.

Nessa direção, a publicação da Seção Educação e diferença: diálogos e perspectivas disponibiliza ao leitor 10 artigos e uma resenha relacionados à contribuição e ao desafio de produzir ciência e pluralizar conhecimentos no campo da pesquisa em educação e suas interfaces com as diferenças.

0 artigo Servicio/trabajo social con niños y niñas con necesidades educativas especiales en España, de Enrique Pastor Seller e Carla Grau Bastida, apresenta uma investigação empírica sobre a realidade do serviço/trabalho social na educação da Espanha. Os resultados revelam, entre outros: a feminização do serviço/trabalho social na Espanha; a presença dos centros e serviços, em sua maioria, de dependência pública; o atendimento no âmbito da evasão escolar, orientação familiar, atenção à diversidade e necessidades educacionais especiais; o desenvolvimento de funções que visam prevenir e abordar problemas individuais dos alunos, com relação ao contexto familiar e escolar; a escassa presença de assistentes sociais no sistema educacional; bem como a falta de reconhecimento dessa figura profissional na educação.

Sob o título 0 que ensinam livros didáticos de Artes do Ensino Médio sobre arte dos povos indígenas, Mariana Schnorr Thomas e lara Tatiana Bonin discutem formas de representação das práticas artísticas dos povos indígenas em dois livros didáticos de Arte para o ensino médio selecionados para distribuição em escolas públicas por meio do Programa Nacional do Livro Didático.

Anfrisia Alessandra Pereira Araujo, María del Carmen Plata Luque, María Luisa Ortiz Mallol e Ana Isabel Jiménez Durán, no artigo intitulado Educación transdisciplinar en valores para la integración de jóvenes en riesgo de exclusión social, descrevem a relevância da integração de jovens dos grupos étnicos cigano e não cigano, em risco de exclusão social, utilizando como núcleo central os valores humanos e a transdisciplinaridade na Espanha. As autoras apontam, a partir de referenciais teóricos da educação, da sociologia e da teoria de sistemas, uma formação e capacitação sistemática em valores no âmbito de uma educação formal inclusiva e participativa. 
Tamiris Maia Gonçalves Pereira, Ordália Cristina Gonçalves Araújo e Elias Nazareno tecem reflexões sobre Transdisciplinaridade e interculturalidade: experiências vividas e compartilhadas no curso de educação intercultural indígena - UFG (2018). Os autores, por meio dos conceitos de transdisciplinaridade e interculturalidade crítica, evidenciam as dinâmicas das aulas sobre o tema contextual Educação Intercultural Bilíngue, evidenciando a contribuição dos estudantes indígenas em sala como representantes de suas epistemologias.

Os lugares e as funções das mulheres negras e indígenas nas imagens disponibilizadas nos livros didáticos dos territórios campesinos do Brasil e da Colômbia é tema do texto de Janssen Felipe Silva, Anna Rita Sartore e Aline Renata dos Santos, intitulado Imagens de mulheres negras e indígenas nos livros didáticos dos territórios campesinos brasileiro e colombiano. A reflexão advinda das funções de mulheres negras e indígenas, retratadas nas imagens dos livros didáticos em análise, desvelaram marcas da patriarcalização que se articulam à interseccionalidade de gênero, de raça-etnia e de território.

Pedro Fernando Santos e Ana Lúcia Oliveira Aguiar apresentam as Histórias que educam: dos velhos do quilombo à formação para a juventude - memória, saberes, tradição. 0 texto problematiza as influências dos saberes da tradição, concretizados pelas "histórias dos velhos" da Comunidade Quilombola de Santana, em Pernambuco, para a formação da juventude dessa localidade. 0 enfoque dado destaca uma forma de educação que não se encontra estritamente na escola, mas foge às fronteiras institucionais e transcende para espaços sociais. No texto, destaca-se uma forma de conhecimento não escolarizado que passa por uma proposta de formação para o exercício da cidadania política, seja tecido de um saber, de uma tradição, seja de histórias que se formaram em um tempo, em um espaço e se reproduzem socialmente.

Na sequência, Liliane Maria Teixeira Lima de Carvalho, Sérgia Andréa Pereira de Oliveira e Carlos Eduardo Ferreira Monteiro socializam os resultados de uma pesquisa desenvolvida em escolas indígenas no texto intitulado Possibilidades da Educação Estatística como forma de análise crítica da realidade na escola indígena. Os autores exploram os aspectos teóricos da Educação Matemática Crítica aliada ao letramento estatístico mediante as expressões socioculturais do povo Xukuru do Ororubá.

E, na linha da educação indigena e formação de professores, Maria Alda Tranquelino da Silva e Eduardo Jorge Lopes da Silva apresentam os Saberes docentes de professores da educação de jovens e adultos indígenas, fazendo referência aos saberes docentes adquiridos na práxis pedagógica por professores indígenas que atuam na educação de jovens e adultos indígenas da Paraiba.

Ações afirmativas e formação de professores: diálogos e perspectivas no NEAB/ UFSCar é o texto disponibilizado por Tatiane Cosentino Rodrigues, Ivanilda Amado Cardoso e 
Andreia Rosalina da Silva. As autoras apresentam uma reflexão crítico-propositiva sobre práticas político-pedagógicas do Núcleo de Estudos Afro-brasileiros da Universidade Federal de São Carlos, SP, e a contribuição para a formação inicial e continuada de professores.

Ao final do bloco dos artigos, Sandro Guimarães de Salles, Saulo Ferreira Feitosa e Rosane Freire Lacerda, no texto intitulado Patrimônio cultural indígena: desafios para uma educação patrimonial decolonial, buscam contribuir para a presença indígena nas políticas patrimoniais apresentando para o leitor uma reflexão crítica sobre a legislação e as políticas públicas nacionais sobre patrimônio e educação patrimonial.

Vânia de Fátima Noronha Alves apresenta, em formato de resenha, a obra organizada por Karine Oliveira, intitulada Raízes - Resistência histórica. A partir da leitura da obra, a autora destaca que o depoimento vivo da luta das mulheres, mais do que a própria escrita, inspira uma forma de resistência, destacando que o processo de produção é um exemplo de que não podemos desistir de nossos sonhos.

Assim, esta Seção intenciona socializar reflexões, investigações científicas e práticas curriculares demonstrando que há um itinerário persecutório de pesquisadores nas sendas das ciências da educação em que as questões relativas às presenças, às heranças e às contribuições dessas populações invisibilizadas são e estão presentes, cujos legados sedimentam qualitativamente as formações inicial e continuada dos docentes.

Ademais, nesse proscênio atual de forte regresso ao pensamento único e ao eurocentrismo, esse conjunto de artigos e resenha enseja açular os ânimos individuais e coletivos de que outro mundo é possível, onde todos possam ser reconhecidos em suas singularidades, diferenças e complementaridades.

Por fim, desejamos que os leitores e interlocutores que se acostam aos temas aqui apresentados possam enriquecer seus estudos e trazer contribuições para os autores que se predispuseram a socializar os resultados de suas investigações, desde o território brasileiro indígena e quilombola até os espaços ciganos de além mar.

Excelente leitura para todos!

\section{REFERÊNCIAS}

ALMEIDA, E. A. A educação escolar indígena nos sistemas de ensino do Brasil. Revista da FAEEBA Educação e Contemporaneidade, Salvador: UNEB, v. 19, n. 33, p. 23-34, jan./jun. 2010.

BRASIL. Lei n. 10.639, de 9 de janeiro de 2003. Altera a Lei n 9.394, de 20 de dezembro de 1996, que estabelece as diretrizes e bases da educação nacional, para incluir no currículo oficial da Rede de Ensino a obrigatoriedade da temática História e Cultura Afro-Brasileira, e dá outras providências. Diário Oficial da República Federativa do Brasil, Brasília, DF, 9 jan. 2003. 
BRASIL. Lei n. 11.645, de 10 de março de 2008. Altera a Lei n. 9.394, de 20 de dezembro de 1996, para incluir no currículo oficial da Rede de Ensino a obrigatoriedade da temática História e Cultura Afro-Brasileira e Indígena. Diário Oficial República Federativa do Brasil, Brasilia, DF, 10 mar. 2008.

BRASIL. Lei n. 9.394, de 20 de dezembro de 1996. Estabelece as diretrizes e bases da educação nacional. Diário Oficial da União, Brasília, DF, 20 dez. 1996.

GOMES, N. L. 0 Movimento Negro Educador: saberes construidos nas lutas por emancipação. Petrópolis, RJ: Vozes, 2017.

GRUPIONI, L. D. B. Educação e povos indígenas: construindo uma política nacional de educação escolar indígena. Revista Brasileira de Estudos Pedagógicos, Brasília, DF, v. 81, n. 198, p. 273-283, maio/ago. 2000.

OLIVEIRA, P. C. de. Gestão territorial indígena: perspectivas e alcances. Estudos indígenas: comparações, interpretações e políticas. São Paulo: Contexto, 2008. p. 175-191. Série Justiça e Desenvolvimento.

SANTIAGO, M. E. et al. (org.). Educação, Escolarização e ldentidade Negra: 10 anos de pesquisa sobre relações raciais no PPGE - UFPE. 1. ed. Recife: Editora Universitária/UFPE, 2010.

SILVA, R. H. D. da. 0 Estado brasileiro e a educação (escolar) indigena: um olhar sobre o Plano Nacional de Educação. Revista Tellus, Campo Grande, v. 2, p. 123-136, 2002.

Endereços para correspondência: Rodovia BR-104, Km 59, Nova Caruaru, 55002-970, Caruaru, Pernambuco, Brasil; jaqueline.barbosa@yahoo.com.br 
